Published in final edited form as:

Addict Res Theory. 2014 ; 22(6): 535-540. doi:10.3109/16066359.2014.926896.

\title{
Binge Drug Use among Street-Involved Youth in a Canadian Setting
}

\author{
Seonaid Nolan ${ }^{1}$, Kora DeBeck ${ }^{1,2}$, Paul Nguyen ${ }^{1}$, Thomas Kerr ${ }^{1,3}$, and Evan Wood ${ }^{1,3}$ \\ ${ }^{1}$ British Columbia Centre for Excellence in HIV/AIDS, St. Paul's Hospital, Vancouver, Canada \\ ${ }^{2}$ School of Public Policy, Simon Fraser University \\ ${ }^{3}$ Department of Medicine, Faculty of Medicine, University of British Columbia, Vancouver, Canada
}

\section{Abstract}

Background-Binge drug use has been associated with increased risk of HIV infection and other serious health-related harms among adult drug user populations. This study sought to determine the prevalence and correlates of binge drug use among street-involved youth in a Canadian setting.

Methods-From Sept 2005 to May 2012, data were collected from the At-Risk Youth Study (ARYS), a prospective cohort of street-involved youth aged 14-26 who use illicit drugs. Multivariate generalized estimating equations (GEE) was used to identify factors associated with binge drug use.

Results-Of the 987 participants included in this analysis, $41.5 \%$ reported binge drug use at baseline, and another $59.1 \%$ reported binge drug use at some point during the study. In multivariate GEE analysis, older age (adjusted odds ratio $[\mathrm{AOR}]=1.11)$, homelessness $(\mathrm{AOR}=$ 1.67), drug injecting ( $\mathrm{AOR}=1.63$ ), non-fatal overdose ( $\mathrm{AOR}=1.98)$, public injecting ( $\mathrm{AOR}$ 1.42 ), being a victim of violence ( $\mathrm{AOR}=1.38)$, sex work $(\mathrm{AOR}=2.51)$ and participation in drug dealing $(\mathrm{AOR}=2.04)$ were independently associated with binge drug use in the previous 6 months (all $\mathrm{p}<0.05$ ).

Discussion-The prevalence of reporting binge drug use among the youth was high in this setting and was independently associated with a range of high-risk activities and markers of vulnerability. Querying high-risk youth about binge drug use may help prioritize those in greatest need of addiction treatment strategies and public health interventions.

\section{Keywords}

binge drug use; injection drug use; street youth; public health; addiction; homelessness

Send correspondence to: Evan Wood, MD, PhD, BC Centre for Excellence in HIV/AIDS, 608 - 1081 Burrard Street, Vancouver BC V6Z 1Y6, Canada, Tel: 604-806-9692, Fax: 604-806-9044, uhri-ew@cfenet.ubc.ca. 


\section{INTRODUCTION}

Approximately, 65,000 youth are without shelter in Canada and residential instability and street involvement places this unique group at high risk for a range of health and social harms (Krüsi, Fast, Small, Wood, \& Kerr, 2010; Rew, 2002). Compared with non-street involved adolescents of similar age, street-involved youth face an eight to eleven times higher risk of mortality (Roy et al., 2004). Sexual risk behaviour is also high resulting in high risk of pregnancy and sexually transmitted infections including human immunodeficiency virus (HIV) (Koopman, Rosario, \& Rotheram-Borus, 1994; Kral, Molnar, Booth, \& Watters, 1997; MacDonald, Fisher, Wells, Doherty, \& Bowie, 1994; Sherman, 1992; Surveillance and Epidemiology Section, Public Health Agency of Canada, 2006). Up to one-third of street-involved youth also report involvement in sex work which, in addition to sexual-related risks, increases vulnerability to violence (Weber, Boivin, Blais, Haley, \& Roy, 2002).

Illicit drug use is also common among this population. Approximately 95 percent of Canadian street youth admit to having ever used non-injection drugs (Surveillance and Epidemiology Section, Public Health Agency of Canada, 2006). Such prevalent substance use can lead to participation in high rates of drug-related risky behaviours including injection drug use and sex work (Debeck et al., 2007; Fischer, Rehm, \& Blitz-Miller, 2000; Shannon, Bright, Gibson, \& Tyndall, 2007) all of which similarly increase the risk for blood born and sexually transmitted infections (Koopman et al., 1994; Kral et al., 1997).

Prior research has demonstrated that specific drug use patterns may predispose individuals to high-risk behaviours (Miller et al., 2006). Binge drug use is one such pattern that has been associated with higher rates of sex work involvement, syringe sharing and HIV incidence in adult drug using populations (Fennema, Van Ameijden, Van Den Hoek, \& Coutinho, 1997; Miller et al., 2006; Wood et al., 2002). Little is known, however, about the prevalence and impacts of binge drug use among street-involved youth. Addressing this knowledge gap could have important implications for public health interventions and addiction treatment strategies to reduce the high rates of health and social harms among this population. Therefore, the present study examined the impacts of binge drug use among a Canadian cohort of street-involved youth.

\section{METHODS}

The present analysis derived data from the At-Risk Youth Study (ARYS), a prospective cohort of street-involved youth in Vancouver, Canada. The cohort began in 2005 and has been described in detail previously (Wood, Stoltz, Montaner, \& Kerr, 2006). In brief, youth were recruited through snowball sampling and extensive street-based outreach methods and were eligible for inclusion if they were between 14 and 26 years at enrolment, report using an illicit drug other than marijuana in the past 30 days and provide written informed consent.

Participants completed an interviewer-administered questionnaire and provided blood samples for HIV and HCV at baseline and bi-annually. The survey is conducted by ARYS staff trained in survey administration and solicits detailed sociodemographic data as well as 
data relating to drug use patterns, sexual and drug-related risk behaviours and engagement with the criminal justice system. Participants are given a \$20 CAD monetary stipend at each study visit. Additionally, if appropriate, participants are also referred to social services, local health or housing programs. The ARYS cohort has been approved by the research ethics board of the University of British Columbia.

Data for this study were collected from participant interviews conducted between September 2005 and May 2012. The primary outcome of interest was binge drug use in the past six months defined as responding "yes" to the question "In the past six months, did you go on runs or binges (that is, when you used non-injection/injection drugs more than usual)?" The comparison group was youth who reported no binge drug use in the last six months.

Explanatory variables of interest included socio-demographic data, age (per year older), gender (female vs. male), Caucasian ethnicity (yes vs. no), and homelessness, defined as being completely homeless (e.g., having no fixed address, sleeping on the street, couch surfing, or staying in a shelter or hostel) at some point in the previous six months (yes vs. no). Drug-use variables refer to behaviours in the previous six months, and included: injection drug use (yes vs. no), non-fatal overdose defined as having experienced a negative reaction from using too much drugs (yes vs. no), syringe sharing defined as having lent a used rig to someone else or having injected with a syringe that had already been used by someone else (yes vs. no) and public injecting defined as injecting drugs in public environments including streets, public lavatories, alleys, parks, parking lots, abandoned buildings, and other public settings (yes vs. no). Other variables considered included: reporting being victim of violence, defined as having been attacked, assaulted, or suffered violence in the previous six months (yes vs. no); reporting police encounters, defined as being stopped, searched or detained by the police in the previous six months (yes vs. no); recent incarceration, defined as being in detention, prison, or jail overnight or longer in the previous six months (yes vs. no); sex work, defined as exchanging sex for any of food, shelter, clothing, money, drugs, favours or gifts (yes vs. no); and participating in drug dealing (yes vs. no).

We first stratified the study sample by baseline binge drug use (i.e., within 6 months prior to study enrolment). Variables potentially associated with reporting baseline binge drug use were examined in bivariate analyses using Pearson's Chi-square test and the Wilcoxon rank sum test. Since repeated measures were available based on the semi-annual follow up visits, we then used generalized estimating equations (GEE) logistic regression to identify factors independently associated with recent binge drug use over study follow-up. Standard errors were adjusted by multiple observations per person using an exchangeable correlation structure. To adjust for potential confounding, all variables that were associated with binge drug use at $p<0.10$ in GEE bivariate analyses were considered in a full model.

Quasilikelihood under the Independence model Criterion (QIC) statistic with a backward model selection procedure was used to identify the model with the best overall fit as indicated by the lowest QIC value (Pan, 2001). To ensure basic demographic factors were adjusted for, age, female gender and Caucasian ethnicity were forced into the model selection procedure and final model. All statistical analyses were performed using SAS software version 9.3 (SAS, Cary, NC). All p-values are two sided. 


\section{RESULTS}

Between September of 2005 and May of 2012, 987 participants were enrolled in the study through ongoing recruitment. Among this sample 311 (31.5\%) were female, 665 (67.4\%) were Caucasian, and the median age was 21 years (interquartile range $[\mathrm{IQR}]=19-23$ ). This sample contributed a total of 3293 study observations. The median number of months of follow-up was 25 (IQR $16-33$ ) and the median number of study visits was 3 (IQR = 1 5 ). The number of youth who reported binge drug use within the preceding six months at baseline was 410 (41.5\%). Over the study period, recent binge drug use (within six months) was reported by $583(59.1 \%)$ youth and a total of 1063 (32.3\%) study observations included a report of recent binge drug use.

Table 1 provides baseline characteristics of all participants stratified by binge drug use in the preceding six months. As shown here, older age, homelessness, drug injecting, non-fatal overdose, hepatitis c positivity, syringe sharing, public injecting, being a victim of violence, reporting encounters with the police, recent incarceration, sex work and drug dealing were all positively associated with reporting binge drug use (all $p<0.05$ ).

The results of the bivariate and multivariate GEE analyses are presented in Table 2. In multivariate GEE analysis, factors that remained positively and independently associated with binge drug use include: age per year older (adjusted odds ratio $[\mathrm{AOR}]=1.11,95 \%$ confidence interval $[\mathrm{CI}]: 1.06-1.15$ ), being homeless (AOR $=1.67,95 \% \mathrm{CI}: 1.40-1.99$ ), drug injection ( $\mathrm{AOR}=1.63,95 \% \mathrm{CI}: 1.24-2.12$ ), experiencing a non-fatal overdose (AOR $=1.98,95 \%$ CI: $1.47-2.67)$, public injecting $(\mathrm{AOR}=1.42,95 \% \mathrm{CI}: 1.06-1.89)$, being a victim of violence $(\mathrm{AOR}=1.38,95 \% \mathrm{CI}: 1.17-1.62)$, sex work $(\mathrm{AOR}=2.51,95 \% \mathrm{CI}$ : $1.82-3.47)$ and participation in drug dealing $(\mathrm{AOR}=2.04,95 \% \mathrm{CI}: 1.72-2.42)$.

\section{DISCUSSION}

This longitudinal study demonstrates that binge drug use is highly prevalent among street involved youth in this setting and was associated with several high-risk behaviors and markers of vulnerability including drug injection, public injecting, non-fatal overdose, homelessness, sex work, drug dealing and being a victim of violence.

While high rates of illicit drug use among street-involved youth have previously been reported (Clatts, Davis, Sotheren, \& Attilasoy, 2008; Embleton, Mwangi, Vreeman, Ayuku, $\&$ Braitstein, 2013), there is a paucity of existing literature on specific drug use patterns that may help identify those at highest risk among this population. To our knowledge, the observations reported herein are the first to not only identify how widespread reports of binge drug use are among street involved youth but also demonstrate that reporting binge drug use is an important independent marker of high-risk behaviour, vulnerability, and health related harms. These findings are consistent with adult studies of injection drug users which indicate that binge drug use is linked with several high-risk behaviours including sex work, public injecting, and non-fatal overdose (Miller et al., 2006; Wood et al., 2002). Our results may be explained by disinhibition and impaired judgement that occur after intense substance use resulting in high-risk behaviors including sexual activities (Koopman et al., 
1994; Kral et al., 1997; Watters, Estilo, Kral, \& Lorvick, 1994). Binging, defined in our study as using more of a substance than usual, appears to only amplify these risks.

Binge drug use was reported by almost half of our participants at baseline and almost 60 percent of participants reported recent binging over the study suggesting this is not a rare occurrence. In comparison to the adult drug using population, these rates are slightly higher. A study by Miller et. al in 2006 found $48 \%$ of adult injection drug users reported binge drug use. Plausible explanations for this are likely related to substance use being common among street involved youth for a number of reasons. Adolescence is a transitional period of ongoing structural and functional maturation of the brain's prefrontal cortex (Casey \& Jones, 2010). This developmental period corresponds with a lack of impulse control and enhanced risk-taking behaviours including drug use (Casey, Jones, \& Hare, 2008; Spear, 2000; Windle et al., 2008). Certain adolescents may also be genetically predisposed and thus more vulnerable to the neurotoxic effects and addictive properties of illicit substances (Newton, O'Leary-Barrett, \& Conrod, 2011; Zeigler et al., 2005). Street youth have often experienced trauma (Stewart et al., 2004) which places them at increased risk for initiating drug use (Hadland et al., 2012; Kerr et al., 2009). Additionally, given the high prevalence of drug use within the social milieu among street youth, drug use itself can become normalized. Such social and environmental influences have previously been shown to be good predictors of substance use (Tyas \& Pederson, 1999). Additionally, the degree to which an adolescent's peers use illicit drugs has been shown to be directly proportional to the amount of substance use the adolescent themself will engage in (Casey \& Jones, 2010).

Our findings also suggest that given their increased likelihood of experiencing homelessness and violence and their reliance on illegal activities for income generation, youth who report binge drug use appear to be a particularly vulnerable group. This further underscores the importance of identifying and implementing public health interventions that can reduce and mitigate the impacts of binge drug use as well as support the overall well being and stability of youth who are susceptible to binge drug use. Examples of such interventions could include shelters or supportive housing for drug using youth given the association found in this study between homelessness and binge drug use. Additionally, drop-in centres could not only provide a temporary relief from environments where binge activity may occur but also offer a safe haven from street predators and other risks of street-violence among streetinvolved youth. Low-threshold employment opportunities may also help mitigate several individual and public health harms given the reliance on sex work and drug dealing among this population. Lastly, while certain addiction treatments have proven effective and should be expanded for opioid using youth (Woody et al., 2008) evidence based addiction treatment strategies for cocaine and methamphetamine addicted youth are urgently required.

There are limitations to our study. ARYS participants were recruited using extensive street based outreach with snowball sampling and are therefore not a random sample. This is similar to other prospective cohorts of street-involved youth however, and significant efforts were made to derive a representative sample (Wood et al., 2006). Furthermore, the variables in our study rely on self-report and are behaviours of a socially sensitive nature. It is therefore possible underreporting occurred as a consequence of either recall or social desirability bias (Des Jarlais et al., 2006). Lastly, while multivariate analysis was used to 
adjust for potential confounders, our results may be influenced by variables not included in our study such as mental illness, genetic variables and other predictors of youth drug use.

In summary, our study demonstrates a high rate of binge drug use among street involved youth and identifies for the first time in this population that this pattern of substance use is independently associated with several high-risk behaviours, markers of vulnerability, and health related harms. These findings highlight the need for evidence-based addiction treatment strategies and public health interventions among street involved youth to reduce harmful patterns of binge drug use and its many negative health and social consequences.

\section{Acknowledgments}

The authors thank the study participants for their contribution to the research, as well as current and past researchers and staff. We would specifically like to thank Cody Callon, Jennifer Matthews, Deborah Graham, Peter Vann, Steve Kain, Tricia Collingham, and Carmen Rock for their research and administrative assistance. The study was supported by the US National Institutes of Health (R01DA028532) and the Canadian Institutes of Health Research (MOP-102742). This research was undertaken, in part, thanks to funding from the Canada Research Chairs program through a Tier 1 Canada Research Chair in Inner City Medicine which supports Dr. Evan Wood. Dr. Kora DeBeck is supported by a MSFHR/St. Paul's Hospital-Providence Health Care Career Scholar Award.

\section{References}

Casey BJ, Jones RM. Neurobiology of the Adolescent Brain and Behavior: Implications for Substance Use Disorders. JAAC. 2010; 49(12):1189-1201.10.1016/j.jaac.2010.08.017

Casey BJ, Jones RM, Hare TA. The Adolescent Brain. Annals of the New York Academy of Sciences. 2008; 1124(1):111-126.10.1196/annals.1440.010 [PubMed: 18400927]

Clatts M, Davis R, Sotheren J, Attilasoy A. Correlates and Distribution of HIV Risk Behaviors Among Homeless Youths in New York City. Implications for Prevention and Policy. 2008:1-14.

Debeck K, Shannon K, Wood E, Li K, Montaner J, Kerr T. Income generating activities of people who inject drugs. Drug and alcohol dependence. 2007; 91(1):50-56.10.1016/j.drugalcdep.2007.05.003 [PubMed: 17561355]

Embleton L, Mwangi A, Vreeman R, Ayuku D, Braitstein P. The epidemiology of substance use among street children in resource-constrained settings: a systematic review and meta-analysis. Addiction (Abingdon, England). 2013 n/a-n/a. 10.1111/add.12252

Fennema JS, Van Ameijden EJ, Van Den Hoek A, Coutinho RA. Young and recent-onset injecting drug users are at higher risk for HIV. Addiction (Abingdon, England). 1997; 92(11):1457-1465.

Fischer B, Rehm J, Blitz-Miller T. Injection drug use and preventive measures: a comparison of Canadian and western European jurisdictions over time. CMAJ: Canadian Medical Association journal = journal de l'Association medicale canadienne. 2000; 162(12):1709-1713.

Hadland SE, Werb D, Kerr T, Fu E, Wang H, Montaner JS, Wood E. Childhood sexual abuse and risk for initiating injection drug use: a prospective cohort study. Preventive Medicine. 2012; 55(5):500 504.10.1016/j.ypmed.2012.08.015 [PubMed: 22954518]

Jarlais Des D, Paone D, Milliken J, Turner C, Miller C, Gribble J, et al. Audio-computer interviewing to measure risk behaviour for HIV among injecting drug users: a quasi-randomised trial. 2006:1-6.

Kerr T, Stoltz JA, Marshall BDL, Lai C, Strathdee SA, Wood E. Childhood trauma and injection drug use among high-risk youth. The Journal of adolescent health: official publication of the Society for Adolescent Medicine. 2009; 45(3):300-302.10.1016/j.jadohealth.2009.03.007 [PubMed: 19699428]

Koopman C, Rosario M, Rotheram-Borus MJ. Alcohol and drug use and sexual behaviors placing runaways at risk for HIV infection. Addictive behaviors. 1994; 19(1):95-103. [PubMed: 8197897]

Kral AH, Molnar BE, Booth RE, Watters JK. Prevalence of sexual risk behaviour and substance use among runaway and homeless adolescents in San Francisco, Denver and New York City. 
International journal of STD \& AIDS. 1997; 8(2):109-117.10.1258/0956462971919651 [PubMed: 9061410]

Krüsi A, Fast D, Small W, Wood E, Kerr T. Social and structural barriers to housing among streetinvolved youth who use illicit drugs. Health \& Social Care in the Community. 2010; 18(3):282288.10.1111/j.1365-2524.2009.00901.x [PubMed: 20102394]

MacDonald NE, Fisher WA, Wells GA, Doherty JA, Bowie WR. Canadian street youth: correlates of sexual risk-taking activity. The Pediatric infectious disease journal. 1994; 13(8):690-697. [PubMed: 7970968]

Miller CL, Kerr T, Frankish JC, Spittal PM, Li K, Schechter MT, Wood E. Binge drug use independently predicts HIV seroconversion among injection drug users: implications for public health strategies. Substance Use \& Misuse. 2006; 41(2):199-210.10.1080/10826080500391795 [PubMed: 16393742]

Newton, NC.; O'Leary-Barrett, M.; Conrod, PJ. Current Topics in Behavioral Neurosciences. Vol. 13. Berlin, Heidelberg: Springer Berlin Heidelberg; 2011. Adolescent Substance Misuse: Neurobiology and Evidence-Based Interventions; p. 685-708.

Pan W. Akaike's information criterion in generalized estimating equations. Biometrics. 2001; 57(1): 120-125. [PubMed: 11252586]

Rew L. Characteristics and health care needs of homeless adolescents. The Nursing clinics of North America. 2002; 37(3):423-431. [PubMed: 12449003]

Roy E, Haley N, Leclerc P, Sochanski B, Boudreau JF, Boivin JF. Mortality in a cohort of street youth in Montreal. JAMA: the journal of the American Medical Association. 2004; 292(5):569-574.

Shannon K, Bright V, Gibson K, Tyndall MW. Sexual and drug-related vulnerabilities for HIV infection among women engaged in survival sex work in Vancouver, Canada. Canadian journal of public health = Revue canadienne de sante publique. 2007; 98(6):465-469. [PubMed: 19039884]

Sherman DJ. The neglected health care needs of street youth. Public health reports (Washington, DC: 1974). 1992; 107(4):433-440.

Spear LP. The adolescent brain and age-related behavioral manifestations. 2000:1-47.

Stewart AJ, Steiman M, Cauce AM, Cochran BN, Whitbeck LB, Hoyt DR. Victimization and posttraumatic stress disorder among homeless adolescents. JAAC. 2004; 43(3):325331.10.1097/00004583-200403000-00015

Surveillance and Epidemiology Section, Community Acuired Infections Division (CAID), Centre for Infectious Disease Prevention and Control, Public Health Agency of Canada. Street Youth in Canada. 2006:1-56.

Tyas S, Pederson L. Psychosocial factors related to adolescent smoking: a critical review of the literature. 1999:1-12.

Watters JK, Estilo MJ, Kral AH, Lorvick JJ. HIV infection among female injection-drug users recruited in community settings. Sexually transmitted diseases. 1994; 21(6):321-328. [PubMed: 7871445]

Weber AE, Boivin JF, Blais L, Haley N, Roy E. HIV risk profile and prostitution among female street youths. Journal of urban health: bulletin of the New York Academy of Medicine. 2002; 79(4):525535.10.1093/jurban/79.4.525 [PubMed: 12468672]

Windle M, Spear LP, Fuligni AJ, Angold A, Brown JD, Pine D, et al. Transitions Into Underage and Problem Drinking: Developmental Processes and Mechanisms Between 10 and 15 Years of Age. PEDIATRICS. 2008; 121(Supplement):S273-S289.10.1542/peds.2007-2243C [PubMed: 18381494]

Wood E, Stoltz JA, Montaner JSG, Kerr T. Evaluating methamphetamine use and risks of injection initiation among street youth: the ARYS study. Harm Reduction Journal. 2006; 3(1): 18.10.1186/1477-7517-3-18 [PubMed: 16723029]

Wood E, Tyndall MW, Spittal PM, Li K, Hogg RS, Montaner JSG, et al. Factors associated with persistent high-risk syringe sharing in the presence of an established needle exchange programme. AIDS (London, England). 2002; 16(6):941-943.

Woody GE, Poole SA, Subramaniam G, Dugosh K, Bogenschutz M, Abbott P, et al. Extended vs short-term buprenorphine-naloxone for treatment of opioid-addicted youth: a randomized trial. 
JAMA: the journal of the American Medical Association. 2008; 300(17):2003-2011.10.1001/ jama.2008.574

Zeigler DW, Wang CC, Yoast RA, Dickinson BD, McCaffree MA, Robinowitz CB, Sterling ML. The neurocognitive effects of alcohol on adolescents and college students. Preventive Medicine. 2005; 40(1):23-32.10.1016/j.ypmed.2004.04.044 [PubMed: 15530577] 


\section{Table 1}

Baseline factors associated with recent binge drug use among street-involved youth in Vancouver $(\mathrm{n}=987)$. $(\mathrm{N}$ =987)

\begin{tabular}{|c|c|c|c|c|}
\hline Characteristic & $\begin{array}{c}\text { No Binge drug use } \\
n=577(\%)\end{array}$ & $\begin{array}{c}\text { Binge drug use } \\
n=410(\%)\end{array}$ & Odds Ratio (95\% CI) & $p$-value \\
\hline \multicolumn{5}{|l|}{ Age } \\
\hline Median (IQR) & $21(19-23)$ & $22(20-24)$ & $1.16(1.10-1.22)$ & $<0.001$ \\
\hline \multicolumn{5}{|l|}{ Gender } \\
\hline Female & $182(31.54)$ & $129(31.46)$ & $1.00(0.76-1.31)$ & 0.979 \\
\hline Male & $395(68.46)$ & $281(68.54)$ & & \\
\hline \multicolumn{5}{|c|}{ Caucasian ethnicity } \\
\hline Yes & $395(68.46)$ & $270(65.85)$ & $0.89(0.68-1.16)$ & 0.390 \\
\hline No & $182(31.54)$ & $140(34.15)$ & & \\
\hline \multicolumn{5}{|l|}{ Homeless ${ }^{*}$} \\
\hline yes & $396(68.63)$ & $330(80.49)$ & $1.89(1.40-2.55)$ & $<0.001$ \\
\hline no & $181(31.37)$ & $80(19.51)$ & & \\
\hline \multicolumn{5}{|l|}{ Drug injection ${ }^{*}$} \\
\hline yes & $121(20.97)$ & $170(41.46)$ & $2.67(2.02-3.53)$ & $<0.001$ \\
\hline no & $456(79.03)$ & $240(58.54)$ & & \\
\hline \multicolumn{5}{|c|}{ Non-fatal overdose ${ }^{*}$} \\
\hline yes & $49(8.49)$ & $61(14.88)$ & $1.88(1.26-2.81)$ & 0.002 \\
\hline no & $528(91.51)$ & $349(85.12)$ & & \\
\hline \multicolumn{5}{|c|}{ Hepatitis C positive } \\
\hline yes & $66(11.44)$ & $98(23.90)$ & $2.43(1.73-3.43)$ & $<0.001$ \\
\hline no & $511(88.56)$ & $312(76.10)$ & & \\
\hline \multicolumn{5}{|l|}{ Syringe sharing ${ }^{*}$} \\
\hline yes & $24(4.16)$ & $55(13.41)$ & $3.57(2.17-5.87)$ & $<0.001$ \\
\hline no & $553(95.84)$ & $355(86.59)$ & & \\
\hline \multicolumn{5}{|l|}{ Public injecting ${ }^{*}$} \\
\hline yes & $83(14.38)$ & $136(33.17)$ & $2.95(2.17-4.03)$ & $<0.001$ \\
\hline no & $494(85.61)$ & $274(66.83)$ & & \\
\hline \multicolumn{5}{|c|}{ Victim of violence ${ }^{*}$} \\
\hline yes & $239(41.42)$ & $202(49.27)$ & $1.37(1.07-1.77)$ & 0.015 \\
\hline no & $338(58.58)$ & $208(50.73)$ & & \\
\hline \multicolumn{5}{|c|}{ Encounters with police ${ }^{*}$} \\
\hline yes & $165(28.60)$ & $174(42.44)$ & $1.84(1.41-2.40)$ & $<0.001$ \\
\hline no & $412(71.40)$ & $236(57.56)$ & & \\
\hline \multicolumn{5}{|l|}{ Incarceration ${ }^{*}$} \\
\hline yes & $84(14.56)$ & $99(24.15)$ & $1.87(1.35-2.58)$ & $<0.001$ \\
\hline No & $493(85.44)$ & $311(75.85)$ & & \\
\hline
\end{tabular}




\begin{tabular}{ccccc}
\hline Characteristic & $\begin{array}{c}\text { No Binge drug use } \\
\mathbf{n = 5 7 7}(\boldsymbol{\%})\end{array}$ & $\begin{array}{c}\text { Binge drug use } \\
\mathbf{n = 4 1 0}(\boldsymbol{\%})\end{array}$ & Odds Ratio (95\% CI) & $\boldsymbol{p}$-value \\
\hline Yes & $37(6.41)$ & $62(15.12)$ & $2.60(1.69-3.99)$ & $<0.001$ \\
No & $540(93.59)$ & $348(84.88)$ & & \\
Drug dealing ${ }^{*}$ & & & & \\
yes & $215(37.26)$ & $214(52.20)$ & $1.84(1.42-2.38)$ & $<0.001$ \\
no & $362(62.74)$ & $196(47.80)$ & & \\
\hline
\end{tabular}

IQR - Interquartile range,

Denotes activities in the previous 6 months 


\section{Table 2}

Bivariate and multivariate GEE analysis of factors associated with recent binge drug use among streetinvolved youth in Vancouver ( $\mathrm{n}=987$ ).

\begin{tabular}{|c|c|c|c|c|}
\hline \multirow[b]{2}{*}{ Characteristic } & \multicolumn{2}{|l|}{ Unadjusted } & \multicolumn{2}{|l|}{ Adjusted } \\
\hline & OR $(95 \% \mathrm{CI})$ & $p$-value & $\operatorname{AOR}(95 \% \mathrm{CI})$ & $p$-value \\
\hline \multicolumn{5}{|l|}{ Age } \\
\hline Per year older & $1.12(1.08-1.16)$ & $<0.001$ & $1.11(1.06-1.15)$ & $<0.001$ \\
\hline \multicolumn{5}{|l|}{ Gender } \\
\hline Female vs. male & $0.87(0.72-1.06)$ & 0.170 & $1.00(0.82-1.23)$ & 0.974 \\
\hline \multicolumn{5}{|l|}{ Caucasian ethnicity } \\
\hline Yes vs. No & $0.95(0.79-1.16)$ & 0.623 & $0.92(0.75-1.12)$ & 0.397 \\
\hline \multicolumn{5}{|l|}{ Homeless * } \\
\hline Yes vs. No & $2.09(1.79-2.44)$ & $<0.001$ & $1.67(1.40-1.99)$ & $<0.001$ \\
\hline \multicolumn{5}{|l|}{ Drug injection ${ }^{*}$} \\
\hline Yes vs. No & $2.56(2.13-3.08)$ & $<0.001$ & $1.63(1.24-2.12)$ & $<0.001$ \\
\hline \multicolumn{5}{|l|}{ Non-fatal overdose ${ }^{*}$} \\
\hline Yes vs. No & $2.67(2.07-3.44)$ & $<0.001$ & $1.98(1.47-2.67)$ & $<0.001$ \\
\hline \multicolumn{5}{|l|}{ Hepatitis $\mathrm{C}$ positive } \\
\hline Yes vs. No & $1.73(1.39-2.15)$ & $<0.001$ & & \\
\hline \multicolumn{5}{|l|}{ Syringe sharing* } \\
\hline Yes vs. No & $2.69(2.03-3.57)$ & $<0.001$ & & \\
\hline \multicolumn{5}{|l|}{ Public injecting ${ }^{*}$} \\
\hline Yes vs. No & $2.88(2.38-3.47)$ & $<0.001$ & $1.42(1.06-1.89)$ & 0.017 \\
\hline \multicolumn{5}{|l|}{ Victim of violence ${ }^{*}$} \\
\hline Yes vs. No & $1.65(1.43-1.92)$ & $<0.001$ & $1.38(1.17-1.62)$ & $<0.001$ \\
\hline \multicolumn{5}{|c|}{ Encounters with police ${ }^{*}$} \\
\hline Yes vs. No & $1.85(1.57-2.19)$ & $<0.001$ & & \\
\hline \multicolumn{5}{|l|}{ Incarceration * } \\
\hline Yes vs. No & $1.64(1.36-1.98)$ & $<0.001$ & $1.22(0.99-1.50)$ & 0.067 \\
\hline \multicolumn{5}{|l|}{ Sex work ${ }^{*}$} \\
\hline Yes vs. No & $3.32(2.48-4.44)$ & $<0.001$ & $2.51(1.82-3.47)$ & $<0.001$ \\
\hline \multicolumn{5}{|l|}{ Drug dealing ${ }^{*}$} \\
\hline Yes vs. No & $2.57(2.19-3.00)$ & $<0.001$ & $2.04(1.72-2.42)$ & $<0.001$ \\
\hline
\end{tabular}

OR - odds ratio, AOR - adjusted odds ratio, CI - confidence interval,

* Denotes activities in the previous 6 months 